\title{
Court case to reclaim confidential data
}

A public-health expert in the United States is facing a potential jail term or a hefty fine after distributing documents that contain safety data on a blockbuster drug. The material came to light during initial negotiations in an ongoing lawsuit over the drug, and its manufacturer says that the information should have remained confidential.

The case, which could result in charges of contempt being levelled against the expert, shines light on the murky debates that go on between lawyers before drug liability cases get to court. Legal experts say that the negotiations often end with crucial data being sealed from public view after lawyers have finished with it, even though they could be relevant to public health.

"Defendants essentially pay for the right to keep stuff secret," says Paul Levy, an attorney with Public Citizen, a consumer-advocacy organization based in Washington DC. "It is a conflict between public and private interests."

The latest incident centres around David Egilman from Brown University in Providence, Rhode Island, who is a frequent critic of the pharmaceutical industry, and Eli Lilly, a drug firm based in Indianapolis, Indiana. Lilly's best-earning drug is Zyprexa, a treatment for schizophrenia that brings in more than US $\$ 4$ billion a year. But over the past two years Lilly has paid $\$ 1.2$ billion to more than 26,000 patients who complained that the drug caused them to develop diabetes and hyperglycaemia. Other lawsuits related to Zyprexa and diabetes are ongoing, including one that Egilman last year agreed to contribute to as an expert witness.

Egilman had access to 15 million pages of confidential documents containing clinical-

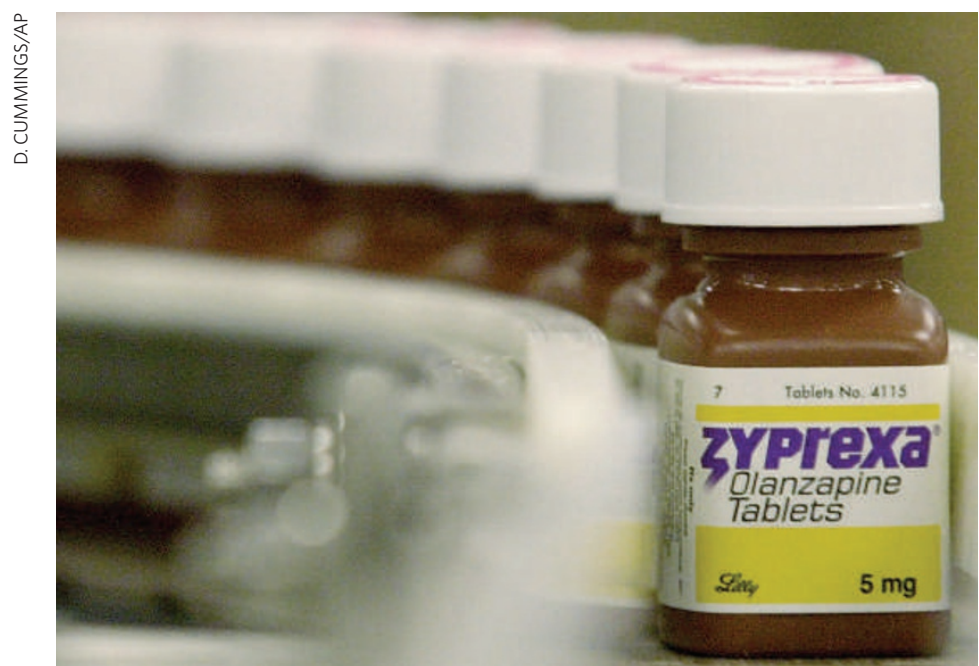
fidentiality agreements. sometimes not been released to

trial data and details of marketing plans that Lilly had released to lawyers during pre-trial negotiations, known as the discovery phase. But because the cases were settled before they reached court, the material was bound by con-

This situation is common and has angered public-health experts and some lawyers. Discovery documents often contain evidence that suggests a drug is not as effective or as safe as its manufacturer claims and the information has regulators such as the US Food and Drug Administration. Yet lawyers are under no obligation to ask for the confidential-

"Defendants essentially pay for the right to keep stuff secret." ity order to be removed, even if the material suggests that the public is at risk.

In the Zyprexa case, 376 documents emerged after what might be called creative journalism by the New York Times. According to a 13 February statement from Jack Weinstein, the New York district judge overseeing the case, Egilman discussed the documents with Alex Berenson, a Times reporter. To get the material, Berenson gave Egilman the name of an attorney who, the judge said, "would be a willing ally in an attempt to avoid the court's protective order by finding a case which could be used as a pretence for subpoenaing the protected documents". The attorney, James Gottstein of Anchorage, Alaska, subpoenaed Egilman for the Zyprexa documents and then forwarded them on to the reporter.

The result was a series of front-page stories in which Berenson alleged that Lilly had downplayed the risks that Zyprexa users would develop diabetes. The stories also claimed that

The schizophrenia drug Zyprexa has rekindled a debate about the confidentiality of documents involved in lawsuits.
Lilly tried to persuade doctors to prescribe the drug for dementia, a condition that it was not licensed for. Lilly spokesman Philip Belt declined to comment on either issue, saying only that the information quoted by Berenson was taken out of context.

Although Egilman was subpoenaed to release the documents, he and Gottstein could face jail terms or be required to contribute to Lilly's legal bills if the contempt proceedings proceed and are upheld. The documents, meanwhile, remain available online on a blog about mental-health issues.

Generally though, information uncovered during the discovery phase remains secret. In a separate instance, psychiatrist David Healy, of Cardiff University in Wales, says that he received confidential documents for several cases on which he was to act as an expert witness. Lawyers in the cases were acting for individuals who claimed that they or their relatives had had suicidal or homicidal thoughts after taking antidepressants known as selective seratonin reuptake inhibitors (SSRIs). All the documents had to go back to the firms that supplied them, but "there is a great deal of material that ought to be out there", says Healy.

Documents have also been sealed in other SSRI cases that were settled before trial and in litigation involving prescription painkillers such as oxycontin and neurontin. And in 2004, publication of a study on cancer risk at an IBM factory was delayed after lawyers for the firm argued that the data were covered by a confidentiality order. "Concealment of such evidence corrupts the scientific literature," says Vera Sharav of the Alliance for Human Research Protection, a patient advocacy group based in New York. (Sharav had also received the documents from Gottstein, but was ordered by Weinstein to return them).

Changing the rules governing discovery documents will be difficult. Discovery material often contains trade secrets, such as details of how a drug is made, as well as records for individual patients. Without confidentiality, defendants would be much more reluctant to give up such materials. "The judge knows that the secrecy is the grease that keeps things moving," says Gottstein. "He doesn't want the settlement to get gummed up."

Critics acknowledge that some material needs to be kept under wraps, but that this should not prevent documents from being released if they are in the public interest. Some legal firms, such as Baum Hedlund in Los Angeles, California, 
